\title{
Conjunctive Utilization of Water Resources at the Yulin Coal-Mine Base in China
}

\author{
Huaqi Wang1,2, Maosheng Zhang1,2, Xueya Dang1,2, Ying Dong1,2 \\ ${ }^{1}$ Xi' an Centre of Geology Survey, China Geology Survey, Xi'an, China \\ ${ }^{2}$ Centre of Water Resources and Environmental Engineering and Technology in Shaanxi Province, Xi'an, China \\ Email: whqi321@163.com
}

How to cite this paper: Wang, H.Q., Zhang, M.S., Dang, X.Y. and Dong, Y. (2018) Conjunctive Utilization of Water Resources at the Yulin Coal-Mine Base in China. Journal of Geoscience and Environment Protection, 6, 15-25. https://doi.org/10.4236/gep.2018.63003

Received: January 29, 2018

Accepted: March 10, 2018

Published: March 13, 2018

\begin{abstract}
Shortages in water resources and the fragile ecosystem by coal-mine water affect the Yulin coal-mine base in northwest China, so taking coal-mine water into account is an important issue for the sustainable management of water resources. This paper aims to explore how the Yulin coal-mine base can improve its conjunctive utilization of water resources. Integrated utilization is proposed by establishing a multi-objective, multi-water-source, optimal-allocation model; setting up an integrated information platform; and giving very useful measures and policy suggestions to the local government. Finally, this research can also serve as an example of integrated water utilization for other energy bases.
\end{abstract}

\section{Keywords}

Conjunctive Utilization of Water Resources, Multi-Objective Optimal Allocation, Integrated Water-Resource-Utilization Information Platform, Coal-Mine Water, Yulin Coal-Mine Base

\section{Introduction}

China is a major country for coal production. In the coal mining process, the massive amounts of mine water used not only waste groundwater but also cause environmental pollution. Moreover, $75 \%$ of mining areas suffer from water shortages. The Jurassic coal field in Yulin city in northern Shaanxi is one of the seven major coal fields in the world. In the flourishing city of Yulin, economic growth is largely a result of non-renewable coal mining and associated activities. Underground mining has induced many geological and environmental problems, such as water contamination, dewatering of aquifers and mine subsidence. Coal mining is accompanied by the generation of mine water, which affects the 
water regime of the area in different ways: disturbing the natural water resources cycle pattern, lowering the water table and polluting surface and subsurface water bodies [1]. Untreated mine-water pollution is one of the most severe forms of aquatic pollution and is a wide spread problem internationally [2] [3] [4]. Mining operations for nearly 20 years in Tibet have caused an impact on the region's surface water quality [5]. In Yulin, most of the mine drainage is discharged as industrial waste water, which can seriously pollute water resources and threaten water quality. Currently, communities around mining areas are commonly more concerned about the impact of mining on their health and livelihoods rather than the monetary or economic benefits of mining [6].

Water is an important resource in mining because most mining activities cannot be completed without water [7]. With the rapid development of Yulin, non-conventional water resources will have a more important role in the future, such as the mine water, recycled water from municipal sources, and brackish groundwater. Thus, in mining regions with water shortages, treated mine-water utilization is very necessary. According to the mine-water analyses, the majority of mine-drainage water contains suspended solids and needs to be purified, which mainly eliminates the suspended matter. Xiu et al. [8] analysed the mine water quality, treatment techniques and integrated management methods in the Shendong coal-mine region. Li X. et al. developed an optimal design and use of the mine water, which can save water resources and avoid deterioration of the environment [9]. Additionally, based on an analysis of the characteristics of mine waste water, Liu et al. developed a new way to purify and utilize mine waste water [10]. Drainage from coal mines is also a significant environmental issue in Yulin and is a huge potential water resource for social, environmental and economic benefits. Therefore, improving the utilization of mine water is consistent with the need for a sustainable society and is necessary to build large coal-mine bases in arid and semi-arid regions.

Water resources are becoming the limiting factor for the development of the Yulin coal-mine base in northern Shaanxi Province, China. Shortages in water resources and the pollution of a fragile ecosystem by the waste and pollution of mine water make taking coal-mine water into account in water-resource utilization an important issue for the sustainable management of water resources. In light of the above discussion and using the Yulin coal-mine base as a case study area, the purpose of this paper is to address the conjunctive utilization of coal-mine water, surface water and groundwater for the sustainable development of the study area.

\section{The Study Area}

Yulin coal-mine base is located in the arid and semi-arid region in northwest China and is close to the borders of four provinces: Gansu, Ningxia, Inner Mongolia and Shaanxi(ranging from $107^{\circ} 28^{\prime}$ to $111^{\circ} 15^{\prime} \mathrm{E}$ and from $36^{\circ} 57^{\prime}$ to $39^{\circ} 34^{\prime} \mathrm{N}$ ), with an approximate area of $43,578 \mathrm{~km}^{2}$ (Figure 1). It belongs to a 


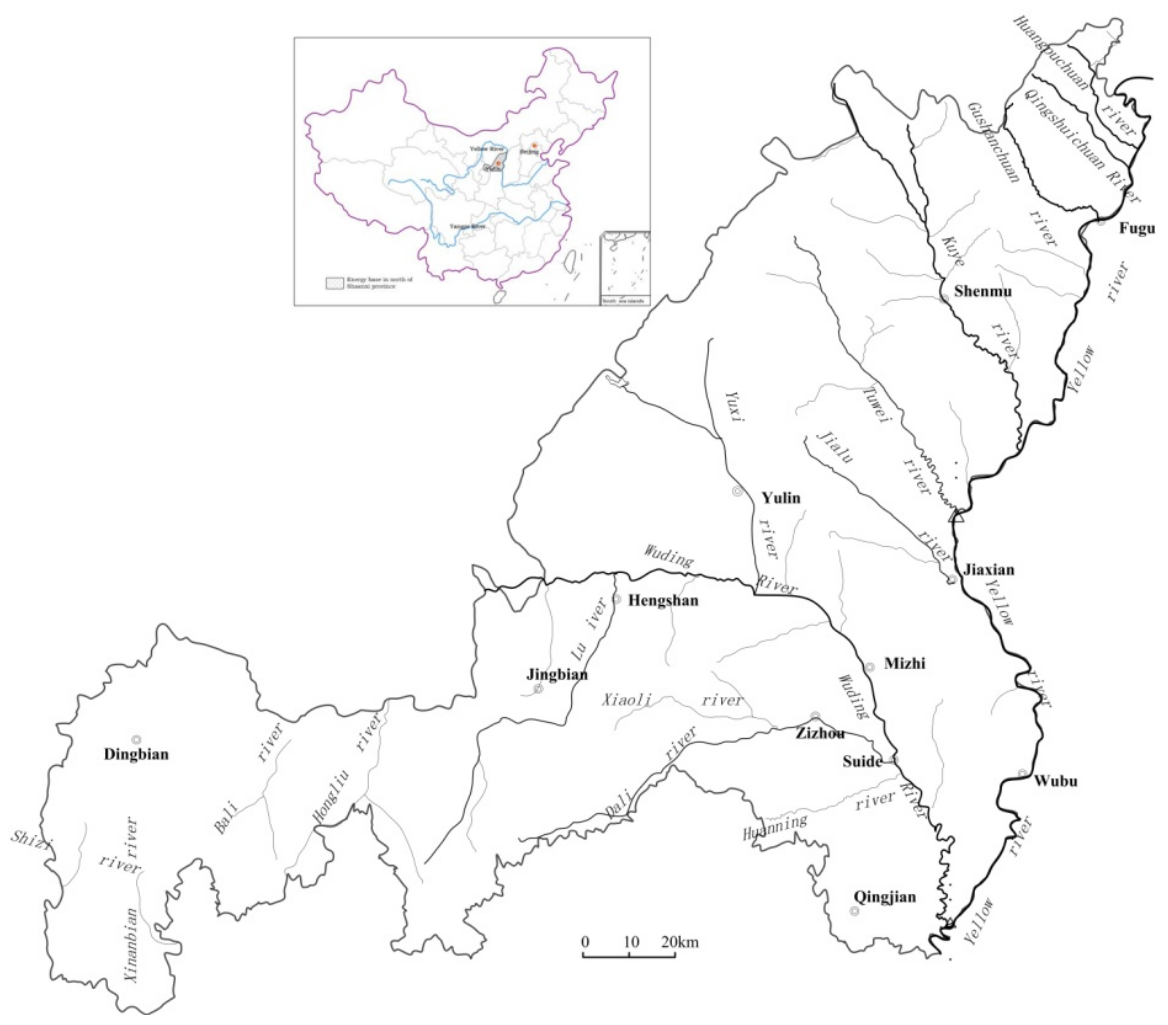

Figure 1. Location of the study area.

transition zone between the $\mathrm{Mu}$ Us Desert and loess plateau areas. Elevation in the region ranges from 585 to $1905 \mathrm{~m}$, sloping generally downwards from the northwest to the southeast. The area has a typical continental, semi-arid monsoon climate. The annual average temperature is approximately $8-10^{\circ} \mathrm{C}$. The mean annual precipitation in the area is between 318 and $485 \mathrm{~mm}$. The limited precipitation mainly occurs from June to September with high intensity and short duration. The annual average evaporation is $1700-2500 \mathrm{~mm}$, which is 5 to 8 times the amount of the annual mean precipitation.

It is widely accepted that mine drainage is one of the most serious environmental concerns [11]. The coal-mine drainage water comes from the ground storage in the initial process of the coal mining. It is from precipitation, infiltration, evaporation and river base-flow. The authors carried out a field investigation at the Yulin coal-mine base. Water samples were analysed in the laboratory following the standard methods. Tables 1-3 list the coal-mine water data of for various parameters, including harmful indicators and major ions in the Kaokaowusu water source area in the Yulin coal-mine base [12]. According to this investigation and subsequent data analysis, turbidity, smell, chemical oxygen demand, volatile phenol, sulphate and fluoride exceed the standard levels, with some coal and rock particles suspended in the mine drainage water. Development of the coal-mine base is accompanied by an increasing trend in mine-drainage pollution. Thus, the appropriate treatment of mine water is essential to meeting the needs of general industry, ecosystem or agricultural irrigation. 
Table 1. Physical indicators of mine water in Kaokaowusu coal mine.

\begin{tabular}{ccccccc}
\hline \multirow{2}{*}{ Item } & Unit & Limit & \multicolumn{2}{c}{ Langwoqu } & Mine & \multicolumn{2}{c}{ Shenyuan Mine } \\
\cline { 3 - 7 } & & & Test value & Result & Test value & Result \\
\hline Chroma & degree & 15 & 5.0 & Normal & 5.0 & Normal \\
$\begin{array}{c}\text { Turbidity } \\
\text { Taste }\end{array}$ & degree & 3 & $>200.0$ & Above standard & 180.0 & Above standard \\
$\begin{array}{c}\text { Material visible to } \\
\text { the naked eye }\end{array}$ & & No peculiar smell & Coal tar odour & Above standard & Coal tar odour & Above standard \\
& & No & Containing coal ash & Above standard & Containing coal ash & Above standard \\
\hline
\end{tabular}

Table 2. Harmful indicators of mine water in Kaokaowusu water source area.

\begin{tabular}{cccccc}
\hline \multirow{2}{*}{ Item } & \multirow{2}{*}{$\begin{array}{c}\text { Limit } \\
(\mathrm{mg} / \mathrm{L})\end{array}$} & \multicolumn{2}{c}{ Langwoqu mine } & \multicolumn{2}{c}{ Shenyuan mine } \\
\cline { 3 - 5 } & 0.001 & Test value $(\mathrm{mg} / \mathrm{L})$ & Result & Test value $(\mathrm{mg} / \mathrm{L})$ & Result \\
\hline $\mathrm{Hg}$ & 0.05 & $<0.001$ & Normal & $<0.001$ & Normal \\
As & 0.05 & $<0.02$ & Normal & $<0.02$ & Normal \\
Cr ${ }^{6+}$ & 0.002 & 0.02 & Normal & 0.03 & Normal \\
Volatile phenol & 0.003 & Above standard & 0.003 & Above standard \\
Cyanide & 0.05 & $<0.002$ & Normal & $<0.002$ & Normal \\
\hline
\end{tabular}

Table 3. Chemical indicators of mine water in Kaokaowusu coal mine.

\begin{tabular}{|c|c|c|c|c|c|c|}
\hline \multirow{2}{*}{ Item } & \multirow{2}{*}{ Unit } & \multirow{2}{*}{$\begin{array}{c}\text { Limit } \\
(\mathrm{mg} / \mathrm{L})\end{array}$} & \multicolumn{2}{|c|}{ Langwoqu Mine } & \multicolumn{2}{|c|}{ Majiagaigou Mine } \\
\hline & & & Test value $(\mathrm{mg} / \mathrm{L})$ & Result & Test value $(\mathrm{mg} / \mathrm{L})$ & Result \\
\hline $\mathrm{pH}$ & & $6.5-8.5$ & 8.1 & Normal & 7.7 & Normal \\
\hline $\mathrm{Fe}$ & $\mathrm{mg} / \mathrm{L}$ & 0.3 & 0.02 & Normal & 0.04 & Normal \\
\hline $\mathrm{Cl}$ & $\mathrm{mg} / \mathrm{L}$ & 250 & 28.36 & Normal & 95.72 & Normal \\
\hline Sulphate & $\mathrm{mg} / \mathrm{L}$ & 250 & 32.08 & Normal & 260.51 & Normal \\
\hline Total dissolved solids & $\mathrm{mg} / \mathrm{L}$ & 1000 & 315.96 & Normal & 683.68 & Normal \\
\hline Total hardness & $\mathrm{mg} / \mathrm{L}$ & 450 & 182.32 & Normal & 339.32 & Normal \\
\hline Chemical oxygen demand & $\mathrm{mg} / \mathrm{L}$ & 3 & 10.99 & Above standard & 3.30 & Above standard \\
\hline $\mathrm{F}^{-}$ & $\mathrm{mg} / \mathrm{L}$ & 1.0 & 0.97 & Normal & 1.10 & Above standard \\
\hline
\end{tabular}

Based on the above data analysis, coal-mine water utilization in the Yulin coal-mine base has two favourable conditions: 1) the quantity of the mining water is relatively stable during the process of the coal exploration, and 2) because the coal mine water is mainly from the aquifer, the quality is similar to the groundwater. The individual items exceeding standards can be treated to meet the standard of industry or irrigation. Mine-water utilization can provide additional environmental, economic and social benefits. It is necessary to treat the mining water based on the local conditions. Obviously, there is a close relationship between surface water, groundwater and mine water in the study area. Therefore, it is important to make integrated plans to achieve optimal utilization 
of multiple water resources.

\section{Conjunctive Utilization of Multiple Water Sources in the Yulin Coal-Mine Base}

This section describes the framework of the model of conjunctive utilization of multiple water resources in the Yulin coal-mine base, which consists of five parts: mine-water availability analysis and treatment, optimal calculation of mine-water resources, optimal allocation of multiple water sources, and the information-system platform for conjunctive utilization of water resources. This model (Figure 2) will provide a method for other energy bases to follow.

\subsection{The Basic Idea of Conjunctive Utilization of Water Resources}

This section analyses the conjunctive use of surface water, ground water and coal-mine water resources. Water resources depend on a complex system that includes many influencing factors; thus, the optimal allocation in a water-resource system requires multi-objective optimization. To achieve optimal allocation of surface water, groundwater and mine water resources, a systematic approach to decision-making is necessary. It is essential to consider both economic benefits and environmental sustainability [13]. In this paper, the overall objective is the maximum combination of social benefit, economic benefit and ecological benefit; the restrictions are mine-exploration safety and environmental protection.

During recent years, a large number of simulation and optimization models have been used for the planning and management of conjunctive water use. Usually, the simulation models are used to get the answer to 'what if?' and optimization models come back with the answer to 'what is the best?' under a particular set of conditions. However, one is unlikely to get an appropriate solution with simulation or optimization techniques alone, and thus the combined use of simulation and optimization models is essential [14].The multi-objective particle swarm optimization (PSO) algorithm was used to implement the multi-objective optimization model. In line with integrated water resource utilization and

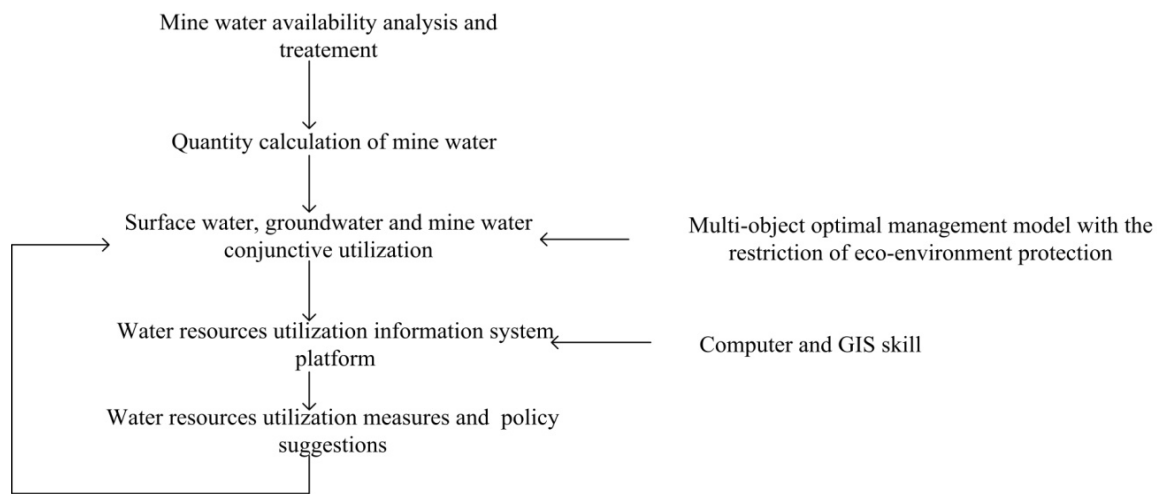

Figure 2. Framework of the model of conjunctive utilization of multiple water sources in the study area. 
management, the information platforms are indispensable. The research focused on integrated utilization by establishing a multi-objective optimal allocation model, establishing an integrated water-resources-management information platform, and giving some useful measures and policy suggestions to the local government.

\section{Economic development based on ecological protection}

Compared to the traditional economy, the great difference of the recycling economy lies in the production process. The traditional economic chain follows a "natural resource $\rightarrow$ product $\rightarrow$ pollutant" way, and is characterized by high-intensity exploitation, low-level utilization, and high emissions. In contrast, in the recycling economy, the production chain is a "resource $\rightarrow$ products $\rightarrow$ renewable resources" feedback flow, characterized by low-intensity exploitation, high-level utilization, and low-emissions [15]. Economic development and environmental security commonly clash, so it is hard for the coal-mining industry and local economy to achieve sustainable development. This research seeks to ensure that the Yulin coal-mine base does not repeat the torturous road of 'developing as well as polluting'. The foundation of sustainable development of the Yulin coal-mine base is ecological protection and harmonious economic development; the core is scientific management, reasonable allocation, efficient utilization and effective protection of water resources.

\section{Who will be responsible for the treatment of contaminated water?}

The development of the mine-water-utilization technology meets the requirements of the green mining, and would have obvious economic and environment benefits. The mine companies are responsible for the contamination, so it is necessary that the mine companies build their own water treatment plant to prevent the polluted water discharging freely. Then, the mine water could be directly pumped into the water treatment plant for the purification, and purified water could be applied to the process of coal production or ecological or agricultural irrigation. A comprehensive mine-water recycling and utilization and green-mining technology should be developed to realize automation in water supply and water drainage applications.

3) The priority of mine-water utilization

In the process of the water conjunctive utilization, compared with surface water and groundwater, the priority should be to use treated coal-mine water.

\subsection{Methodology}

\section{Multi-objective optimization}

It is a challenge to achieve the scientific and reasonable utilization of water resources with sustainable economic and social development without affecting the environment. The key problem is achieving multi-objective optimal allocation. Based on high quality data sets and relatively cost-effective survey results, this research developed a multi-objective and multi-source water-utilization model for the Yulin coal-mine base. According to the multi-rule theory, the 
weights of water-resource uses were determined using the Analytic Hierarchy Process (AHP) method. Under the premise of the harmonious development of humanity, water and ecology, an improved multi-objective particle group algorithm was adopted to simulate the model.

Object function. The main object function is

$$
z=o p t\left\{f_{1}(x), f_{2}(x)\right\}
$$

This takes the direct water supply benefit as the economic object. The formula is expressed as

$$
\max f_{1}(x)=\min \left(-f_{1}(x)\right)=\min \left(-\sum_{k=1}^{k} \sum_{j=1}^{J(k)} \sum_{i=1}^{I(i)}\left(b_{i j}^{k}-c_{i j}^{k}\right) x_{i j}^{k} \alpha_{i}^{k} \beta_{j}^{k} w_{k}\right)
$$

where $x_{i j}^{k}$ is the water supply, $b_{i j}^{k}$ is the benefit coefficient, $c_{i j}^{k}$ is the cost coefficient, $\alpha_{i}^{k}$ is the sequence of the water supply coefficient, $\beta_{j}^{k}$ is the water use equitable coefficient, $w_{k}$ is the weight, $k$ is the number of the water user system, $I(k)$ is the number of water sources and $J(k)$ is the number of water users.

It is difficult to quantify the societal benefit. The degree of water shortage will influence the development of the society, so the minimum water shortage degree is taken as the society object. The formula is

$$
\min f_{2}(x)=\sum_{k=1}^{k} \sum_{j=1}^{J(k)}\left[\frac{D_{j}^{k}-\sum_{i=1}^{I(i)} x_{i j}^{k}}{D_{j}^{k}}\right]^{2}
$$

where $D_{j}^{k}$ is water demand and $x_{i j}^{k}$ is water supply.

The ecological object is reflected in the sequence of ecosystem water supply.

Restrictions. The main restrictions are as follows,

The restriction of the water supply guarantee rate is set as follows: life-water-supply guarantee rate as $98 \%$, the ecological-water-supply guarantee rate as $97 \%$, the industrial-water-supply guarantee rate as $95 \%$ and the agricultural-water-supply guarantee rate as $75 \%$.

The restriction of water supply capacity is set by the formula

$$
\sum_{j=1}^{J(k)} x_{i j}^{k} \leq K G_{i}^{k}
$$

where $x_{i j}^{k}$ is the water supply and $K G_{i}^{k}$ is water supply capacity.

There is a non-negative constraint, namely

$$
x_{i j}^{k} \geq 0
$$

The information platform for conjunctive utilization of water resources

To satisfy the need of the sustainable development, it is urgent to establish an information platform for conjunctive utilization of water resources in the Yulin coal-mine base. Research findings obtained using ArcGIS, intelligent computing and information-management applications in such platforms are becoming increasingly abundant, which provides good theoretical and technical support for 
this research. Some problems still exist in the platform in the Yulin coal-mine base: 1) there is a lack of a scientific information platform for multiple users, and 2) the contradiction between the waste of mine water and the shortage of water resources is becoming increasingly serious. Thus, how to make full use of the drainage water is an urgent challenge.

To enhance the quality of water-resource management, coordination, decision-making and planning, the platform focuses on these two components: 1) a spatial database and statistics database of water resources and 2) the information system for experts, governors and the public, which can provide a basis for reasonable utilization and management of water resources. In this research, this information-system platform includes water-resource-information sharing, database management and optimization of decision-making. The subsystems are as follows: a dynamical layer for browsing and displaying subsystem, a water-resource-monitoring subsystem, a hydrological-forecasting subsystem and a water-resource optimal-allocation subsystem. The framework of the system platform is shown in Figure 3.

This research provides a sharing platform for water-resource-management decision-making in the study area. The innovative achievements are as follows:

1) Based on the analysis of water-resource demand and the relationship between precipitation, surface water, groundwater and mine water, a platform was established with a combination of the browser/server (B/S) and client/server $(\mathrm{C} / \mathrm{S})$ structures.

2) According to the groundwater-monitoring network, the research developed a subsystem with dynamic data collection, wireless transmission, analysis and evaluation, which also determined the groundwater threshold-level in terms of ecology protection.

3) Based on real-time hydrological monitoring, the study implemented a system for dynamic monitoring, information management, inquiry and forecasting for surface water using a support vector machine method and improved back propagation neural network, which allows users to freely choose the forecasting method.

4) The study also developed a platform for optimal allocation-sharing of mine-water resources. The methods included the multi-rule theory, AHP and improved multi-objective particle group algorithm.

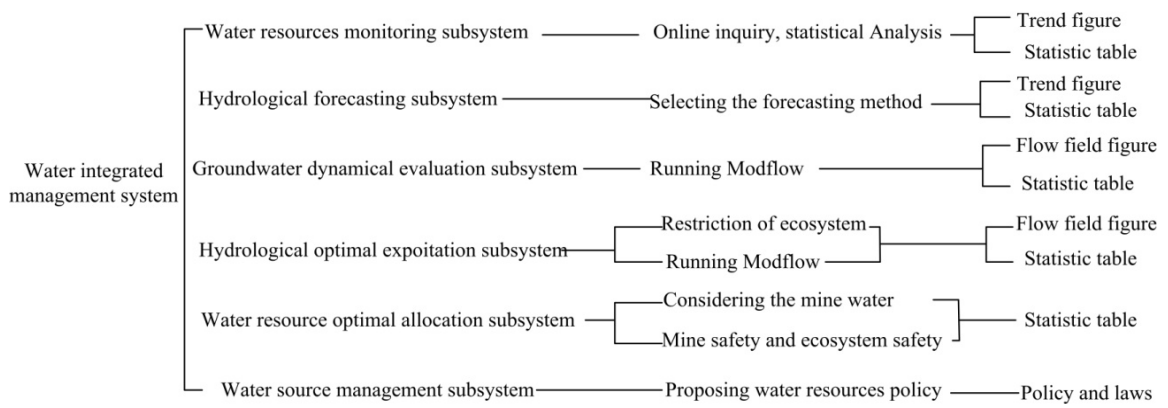

Figure 3. Framework of the water-utilization information-system platform. 


\subsection{Benefit Analysis of Water Conjunctive Utilization}

Base on the survey data of the Yulin coal-mine base (Zhang Maosheng, 2010), this paper forecast the coal-mine water resources. The results indicate that coal-mine water in the Yulin coal-mine base is up to $1.72 \times 10^{8} \mathrm{~m}^{3}$, which can support the production of $17 \times 10^{8} \mathrm{t}$ of coal or an urban population of $4.23 \times 10^{6}$ in one year.

Mine-water utilization can relieve the water shortages, satisfy the demand of industry, agriculture and ecology, and promote social harmony and stability. Through the concept of conjunctive utilization of multiple water sources, water conservation will penetrate into the awareness of the local people. Integrated water management will also stimulate social and economic development and produce more social and economic benefits.

The Yulin coal-mine base is in arid and semi-arid areas, and the ecological environment is fragile. Water is a critical factor to the ecosystem. Coal-mine-water reuse can promote a virtuous circle of ecological sustainability. The ecological benefit is obvious in this coal-mine base.

\section{Conclusions and Discussion}

\subsection{Conclusions}

This conjunctive utilization of surface water, ground water and coal-mine water provides an effective tool for a more reasonable exploitation and utilization of limited water resources in Yulin coal-mine base. This research established a multiple-water-sources utilization model and information platform for the study area. This approach addressed the need for sustainable development of the study area. The above analysis and results demonstrate that mine water can be used to effectively solve the issues of water shortage and contamination. Furthermore, this model provides a good example for management and development of other energy bases.

It is necessary to treat the coal-mine water to meet the standards of industrial, agricultural or ecological water demands and then supply the water to the local coal mine company or nearby farmers. Doing so will also stimulate social and economic development and produce more social and economic benefits.

Authoritative, efficient, coordinated management and operation mechanisms should be established and improved for the basin, and unified management and control of water resources should be implemented.

\subsection{Discussion}

Conjunctive utilization with the coal-mine water must be initiated by taking necessary policy and project measures. Many suggestions are proposed, such as enhancing water conservation awareness, prioritizing mine-water resources, implementing water-resource utilization and information management of industrial planning consistent with the condition of water resources, and strengthening water resources monitoring. 
Water-resource utilization should involve the integrated management of surface water, groundwater, coal-mine water and other water sources in accordance with sustainable development principles, which will obtain the greatest social, economic and environmental benefits. Enhancing the water-conservation awareness of society, especially the mine company, is necessary to achieve this goal. It is important to push forward the industrial and living water-saving technologies, strictly restrain new projects with high pollution and water consumption, promote new water-saving technology, research and develop the new equipment to reduce water use, advocate agricultural water saving technology, and constantly improve water quality and standards.

Industrial development and planning should be consistent with the condition of water resources. Economic and social development should be consistent with the condition of water resources. In the Yulin coal-mine base, the planning of the coal mine, chemical industry, thermal power plant, etc., should be suitable to the conditions of the water resources and place equal emphasis on water resources and environmental conservation. The local government needs to develop policies or standards about mine-water utilization.

Water-resources monitoring promotes the sustainable utilization of surface water, ground-water, mine water and the other water sources in the study area. Water-resource monitoring projects collect water quality and quantity data and make the data publicly available.

\section{Acknowledgements}

This research is funded by a grant from the Key Project of National Natural Science Foundation of China (41530640), and the Science Program Project of Shaanxi Province (2015KJXX-70). In addition, the authors are grateful to Professors Qian Hui and Li Peiyue and the other anonymous reviewers for their helpful comments on improving the manuscript.

\section{References}

[1] Sheoran, V. and Tholia, N.K. (2011) Acid Mine Drainage, an Overview of Indian Mining Industry. International Journal of Earth Sciences and Engineering, 4, 1075-1086.

[2] Jarvis A.P. and Younger, P.L. (2000) Broadening the Scope of Mine Water Environmental Impact Assessment: A UK Perspective. Environmental Impact Assessment Review, 20, 85-96. https://doi.org/10.1016/S0195-9255(99)00032-3

[3] Zhang, J. and Shen, B. (2004) Coal Mining Under Aquifers in China: A Case Study. International Journal of Rock Mechanics and Mining Sciences, 41, 629-639. https://doi.org/10.1016/j.ijrmms.2003.01.005

[4] Dutta, M., Saikia, J., Taffarel, S.R., et al. (2017) Environmental Assessment and Nano-Miner a Logical Characterization of Coal, over Burden and Sediment from Indian Coal Mining Acid Drainage. Geoscience Frontiers, xxx, 1-13.

[5] Huang, X., Sillanpää, M., Gjessing, E.T., Peräniemi, S. and Vogt, R.D. (2010) Environmental Impact of Mining Activities on the Surface Water Quality in Tibet: Gyamavalley. Science of the Total Environment, 408, 4177-4184. 
https://doi.org/10.1016/j.scitotenv.2010.05.015

[6] Liphadzi, S.M. and Vermaak, A.P. (2017) Assessment of Employees' Perceptions of Approaches to Sustainable Water Management by Coal and Iron Ore Mining Companies. Journal of Cleaner Production, 153, 608-625.

https://doi.org/10.1016/j.jclepro.2015.01.037

[7] Watson, A. (2008) Incorporating Sustainability into Mining Services. Eng. Min. J, 209, 106-112.

[8] Xiu, H. and Zhu, Z. (2009) Recycle on High-Salinity Mine Water in Shendong Mining Area. Energy Environmental Protection, 23, 31-33.

[9] Li, X., Li, D. and Fu, Z. (2010) Huainan Mining Area in the Comprehensive Utilization of Water Resources, New Exploration. Coal Technology, 29, 225-226. (In Chinese).

[10] Liu, Y., Han, B. and Cao, J. (2003) Study on Exploitation and Utilization of Mine Wastewater. Pollution Control Technology, 16, 88-91.

[11] Gomo, M. and Vermeulen, D. (2014) Hydrogeochemical Characteristics of a Flooded Underground Coal Mine Ground Water System. Journal of African Earth Sciences, 92, 68-75. https://doi.org/10.1016/j.jafrearsci.2014.01.014

[12] Zhang, M., Dang, X., Wei, X., et al. (2010) Shanbei Energy Chemical Base Groundwater Exploration. Xi'an Centre of China Geological Survey, China Geological Survey.

[13] Li, P., Qian, H. and Zhou, W. (2017) Finding Harmony between the Environment and Humanity: An Introduction to the Thematic Issue of the Silk Road. Environ Earth Sci, 76, 105. https://doi.org/10.1007/s12665-017-6428-9

[14] Singh, A. (2014) Simulation Optimization Modeling for Conjunctive Water Use Management. Agricultural Water Management, 141, 23-29. https://doi.org/10.1016/j.agwat.2014.04.003

[15] Liu, H.B. and Liu, Z.L. (2010) Recycling Utilization Patterns of Coal Mining Waste in China. Resources, Conservation and Recycling, 54, 1331-1340. https://doi.org/10.1016/j.resconrec.2010.05.005 